\title{
The Association between Selected Body Impairments and Self Assessed Health among the Elderly Population
}

\author{
Braja Mohan Otta ${ }^{1}$ \\ ${ }^{1}$ Fakir Mohan University, Balasore, India \\ Correspondence: Braja Mohan Otta, Fakir Mohan University, Balasore 756020, India. E-mail: \\ brajamohanotta@gmail.com
}

Received: January 9, 2012

Accepted: February 19, $2012 \quad$ Published: May 1, 2012

doi:10.5539/ass.v8n6p240

URL: http://dx.doi.org/10.5539/ass.v8n6p240

The present research is supported by the University Grants Commission of India.

\begin{abstract}
Impairment is a medical condition in the disablement process. 'Self Assessed Health' (SAH) is an individual's comprehensive assessment of own general health status. Several studies suggest a fairly good relationship between SAH and objective assessment of health. However, it is not known if such a relationship holds good in the Indian context. The objectives of the present study are to examine the levels of selected body impairment among the elderly population and to study the association between impairment and SAH. Data for the study were collected from 2028 aged respondents of both the sex from Cuttack city of Odisha state under the Indian Union.

Logistic regression of SAH on different levels of impairments suggests that near-vision, hearing, speaking, and biting-chewing food are not significant predictors of self assessed good health. On the other hand, distance vision, distance hearing, climbing a flight of stairs, bending-kneeling on the floor and lifting-carrying a shopping bag are significant predictors of self assessed good health.
\end{abstract}

Keywords: self assessed health, disability, body impairment

Impairment is a medical condition that refers to a loss or abnormality in the psychological, anatomical or physiological structure or function leading to disability. 'Self Assessed Health' (SAH) is an individual's comprehensive assessment of own general health status. The term is also sometimes referred to as 'subjective health', 'self perceived health' or 'self rated health'. The importance of term arises from the fact that there is supposed to exist an association between self and objective assessment of health. Thus SAH may be taken as a quick and proxy measure of general health condition in the absence of any objective measure. It may also be argued that since physician's assessment merely deals with the physical aspect of health and does not capture the social and psychological dimensions of health, SAH may be taken as a better measure as it incorporates all the three dimensions of health as conceived by the World Health Organization (WHO, 1948).

Several studies have brought out a relationship between self and the objective assessment of health. A fifteen year longitudinal study on ambulatory elderly population by Maddox and Douglas (1973) indicated that there existed nearly sixty-five per cent agreements between self assessment and physician's assessment of health. Suchman and others (1958) stated that the agreement may be to the tune of seventy per cent. Similar findings were also reported by Friedsman \& Martin (1963). Mossey and Shapiro (1982) reported that SAH is not only related to various health measures but also to mortality as well. Idler \& Benyamini (1997) and Benyamini \& Idler (1999) after reviewing a number of studies on the relationship between SAH and mortality concluded that there exists an independent effect of SAH on mortality. Those reporting higher SAH are likely to survive longer than those reporting lower SAH. It is not known if this relationship between objective assessment and self assessment also holds good for a poor state like Odisha under the Indian union. The objectives of the present study are firstly to examine the levels of common body impairment among the elderly population and secondly to study the association between body impairment and self assessed health.

The present study is a part of a larger research project on 'The Influence of Sex, Social Position and Life Style on Disability in Old Age'. Data for the project was collected from the Cuttack city of Odisha state under the Indian Union. Cuttack is the oldest city of Odisha state and believed to be 1000 years old. Being old, it is 
unplanned and lacks most modern facilities. Although the Census of India has classified Cuttack to be an urban area but sociologically it has both urban and rural characteristics. Certainly, Cuttack represents the true characteristics of Odisha which is more rural than urban.

The overall sample size for the present study was originally fixed at 2000 with 1000 from either sex. This size was fixed on the logic that 1000 is the minimum required sample for any robust estimation of population \& health indicators. This sample target was raised to 2200 (ten per cent extra) to accommodate for no response or incomplete data. A multistage sampling procedure was adopted. In the first stage, the municipality wards were identified in the city. The city has fifty-four wards and all the wards were selected for data collection. The size of sample from each ward was proportionate to its population and consisted of fifty percent from either sex. In the second stage of sampling, the localities or streets were identified at random after obtaining a list of localities from the municipality records. A complete house listing was conducted in the selected localities. If the required sample size of aged population i.e. 60 years and above was not met from the selected locality, the adjacent locality was picked up from the same ward and this continued until the required sample size was met. After rejecting for the incomplete cases, 2028 cases were finally available for analysis.

As a part of the survey the respondents were asked to state their overall health status on a five point scale starting from 'very bad' to 'very good'. The SAH Index for each respondent was calculated by assigning appropriate weights that ranged between 1 and 5 .

The limitations in body function were calculated by asking the respondents to state if they had any difficulty in eleven selected body functions such as seeing, hearing, speaking, locomotion, biting, grasping, bending, lifting etc. The response to these questions were also in the form of five point scales starting from 'No difficulty', 'Mild difficulty', 'Moderate difficulty',' Severe difficulty' and 'Extreme difficulty'. The impairment index for each of the 11 body functions were calculated by assigning appropriate weights. The total impairment index was the sum of the individual impairment indexes.

The Standard of Living Index (SLI) was computed by adding responses to questions relating to type of house, type of toilet, source of lighting, type of fuel used for cooking, source of drinking water, whether has separate room for cooking, ownership of house, ownership of agricultural land, ownership of irrigated land, ownership of livestock and ownership of household durable goods. Possible responses were pre coded and weights were assigned. The weighted average to these multiple parameters formed the SLI score of the respondents. The SLI score ranged between 3 and 53 with a mean score of 22.46 and standard deviation of 10.21. Based on the SLI score the respondents were divided into three classes namely low, medium and high.

Table 1 presents the mean value of SAH for all the three levels of SLI by age and sex. The data indicates that as age increases, the value of self assessed health comes down. This is not only true for the population as a whole but also for every SLI within the total population. The data further reveals that at every age, higher the standard of living, higher is the SAH value. Again, within each SLI and each age group, the value of SAH is higher for the male than the female. It is evident that age, sex as well as standard of living affect self assessed health.

Table 1. Mean value of self assessed health (By age, sex \& standard of living)

\begin{tabular}{|c|c|c|c|c|c|c|c|c|}
\hline \multirow{2}{*}{$\begin{array}{l}\text { Standard } \\
\text { of Living }\end{array}$} & \multirow[b]{2}{*}{ Sex } & \multicolumn{6}{|c|}{ Age Group } & \multirow{2}{*}{$\begin{array}{r}\text { All } \\
\text { Ages }\end{array}$} \\
\hline & & $60-64$ & $65-69$ & $70-74$ & $75-79$ & $80-84$ & $85+$ & \\
\hline \multirow[t]{3}{*}{ Low } & Male & 3.22 & 2.78 & 2.70 & 2.50 & 1.80 & 1.50 & 2.73 \\
\hline & Female & 3.05 & 2.49 & 2.26 & 1.87 & 2.16 & 1.86 & 2.54 \\
\hline & Persons & 3.12 & 2.62 & 2.44 & 2.13 & 1.95 & 1.65 & 2.62 \\
\hline \multirow[t]{3}{*}{ Medium } & Male & 3.39 & 3.25 & 2.65 & 2.48 & 2.38 & 2.07 & 3.01 \\
\hline & Female & 3.31 & 3.05 & 2.47 & 2.31 & 2.41 & 2.67 & 2.91 \\
\hline & Persons & 3.35 & 3.17 & 2.56 & 2.39 & 2.39 & 2.37 & 2.96 \\
\hline \multirow[t]{3}{*}{ High } & Male & 3.59 & 3.47 & 3.03 & 2.38 & 2.33 & 2.38 & 3.13 \\
\hline & Female & 3.50 & 3.15 & 2.53 & 2.50 & 2.56 & 2.09 & 3.00 \\
\hline & Persons & 3.54 & 3.35 & 2.84 & 2.43 & 2.44 & 2.26 & 3.08 \\
\hline TOTAL & & 3.33 & 3.07 & 2.60 & 2.33 & 2.28 & 2.16 & 2.90 \\
\hline
\end{tabular}


The mean impairment score as discussed earlier is the sum of all the eleven body impairments scores. The scores for the population as a whole and for the sexes by age and standard of living are presented in Table 2 . There are few important observations. Impairment index of female is higher than that of the male in ten out of eleven categories of body function. It is only in hearing a conversation that there is no difference between the male and the female. Interestingly, compared to all other impairments, hearing a conversation has the lowest impairment score. The data also suggests that there exists an inverse relationship between SLI and Impairment. As the standard of living increases, the impairment index comes down, suggesting that impairment affects the poor more than the rich. This is true for all the eleven types of impairments. Between age and impairment, there also exists a direct relationship. In all the eleven categories of impairment, as age advances, the level of impairment goes up.

Table 2. Mean impairment index (By age, sex and standard of living)

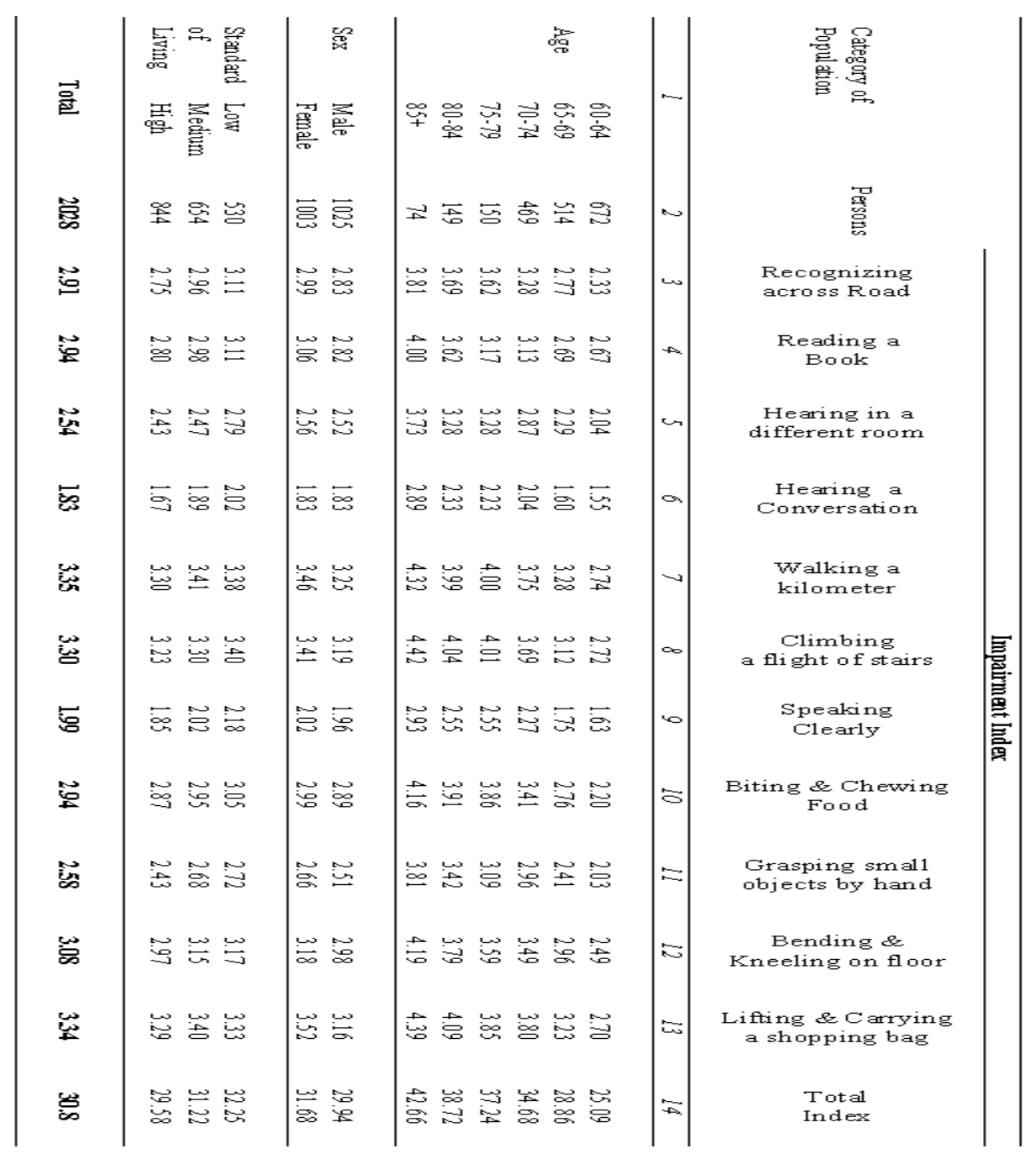

Table 3 presents the odds ratio derived out of logistic regression of 'self assessed health' on different levels of eleven selected impairments. The regression analysis suggests that not all body impairments are likely to affect self assessed health equally. Near vision i.e. ability to read a book or news paper, ability to hear an inter personal verbal conversation, ability to speak clearly and ability to bite-chew food are not significant predictors of self assessed good health as the values are not statistically significant. Grasping small objects in hand may be statistically significant but the odds ratio of self assessing one's health as 'good' for those who have no difficulty, mild difficulty, moderate difficulty and severe difficulty are only $0.215,0.230,0.289$ and 0.355 times over those who have extreme difficulty in grasping small objects in hand. On the other hand, those who have no difficulty in distant vision are 5.792 times more likely to report their health as 'good' compared to those who have extreme difficulty in distant vision. Similarly, those who have no problem in 'distance hearing', 'climbing a flight of 
stairs', 'bending-kneeling on the floor' and 'lifting-carrying a shopping bag' are most likely to assess their as 'good' compared to those who have extreme difficulty.

Table 3. Odds ratio derived from logistic regressions of self assessed health on different levels of selected eleven impairments

\begin{tabular}{|c|c|c|c|c|}
\hline Variables and Categories & $\begin{array}{l}\text { No } \\
\text { Difficulty }\end{array}$ & $\begin{array}{l}\text { Mild } \\
\text { Difficulty }\end{array}$ & $\begin{array}{l}\text { Moderate } \\
\text { Difficulty }\end{array}$ & $\begin{array}{l}\text { Severe } \\
\text { Difficulty }\end{array}$ \\
\hline Recognizing a person Across the Road & $5.792 * * *$ & $6.842 * * *$ & $5.802 * * *$ & $2.222 * *$ \\
\hline Reading a book or News Paper & NS & NS & NS & NS \\
\hline Hearing in a different room & $4.730 * * *$ & $2.968^{* *}$ & $3.475 * * *$ & $1.957^{* *}$ \\
\hline Hearing a Conversation & NS & NS & NS & NS \\
\hline Walking a Kilometer & NS & $2.410^{* *}$ & $2.497 * * *$ & $1.819^{* *}$ \\
\hline Climbing Stairs & $6.125 * * *$ & $4.904 * * *$ & $2.263^{* *}$ & $1.722 * *$ \\
\hline Speaking Clearly & NS & NS & NS & NS \\
\hline Biting \& Chewing Food & $0.319 * * *$ & NS & $1.641^{*}$ & NS \\
\hline Grasping small objects in Hand & $0.215 * * *$ & $0.230 * * *$ & $0.289 * * *$ & $0.355^{* *}$ \\
\hline Bending \& kneeling On the floor & $6.948 * * *$ & $3.300 * * *$ & $2.491 * * *$ & $1.754 * *$ \\
\hline Lifting \& Carrying A shopping bag & $2.985 * * *$ & $3.011 * * *$ & $2.260 * * *$ & $1.718^{* *}$ \\
\hline
\end{tabular}

Note: ${ }^{* * *} \mathrm{p}<.01 ; * * \mathrm{p}<.05 ;{ }^{*} \mathrm{p}<.1$; NS: Not Significant Reference Category for all the explanatory variables is 'Extreme Difficulty'

\section{References}

Benyamini,Y., \& Idler, E.L. (1999). Community Studies Reporting Association between Self Rated health and Mortality: Additional studies, 1995-1998. Research on Ageing, 21(3), 392-401. http://dx.doi.org/10.1177/0164027599213002

Friedsam, H., \& Martin, H. (1963). A Comparison of Self and Physician's Health Ratings in an older population. Journal of Human Social Behaviour, 4, 179-183. http://dx.doi.org/10.2307/2948660

Idler, E.L., \& Benyamini, Y. (1997). Self Rated Health \& Mortality: A review of twenty-seven Community Studies. Journal of Health \& Social Behaviour, 38(1), 21-37. Retrieved from http://www.jstor.org/stable/ 2955359

Maddox, G.L., \& Douglas, E.B. (1973). Self Assessment of Health: A Longitudinal Study. Journal of Health \& Social Behaviour, 14(1), 87-93. http://dx.doi.org/10.2307/2136940

Mossey, J. M., \& Shapiro, E. (1982). Self-rated Health: A predictor of Mortality among the Elderly. American Journal of Public Health, 72(8), 800-808. http://dx.doi.org/10.2105/AJPH.72.8.800

Suchman, E., Phillips, B., \& Streib, G. (1958). An Analysis of the Validity of Health Questionnaires. Social Forces, 36(3), 223-232. http://dx.doi.org/10. 2307/ 2573809

WHO. (1948). Constitution of the World Health Organization - Basic Documents (Forty-fifth ed.), Supplement, October 2006. Retrieved from http://www. who.int/governance/ eb/who_constitution_en.pdf 